\title{
FOREWORD
}

AMARTYA SEN

"Every man who lives is born to die," wrote John Dryden, some three hundred years ago. That recognition is tragic enough, but the reality is sadder still. We try to pack in a few worthwhile things between birth and death, and quite often succeed. It is, however, hard to achieve anything significant if, as in sub-Saharan Africa, the median age at death is less than five years. ${ }^{1}$ That, I should explain, was the number in Africa in the early I990s, before the AIDS epidemic hit hard, making the chances worse and worse. It is difficult to get reliable statistics, but the evidence is that the odds are continuing to fall from the already dismal numbers. Having made it beyond those early years, it may be difficult for us to imagine how restricted a life so many of our fellow human beings lead, what little living they manage to do. There is, of course, the wonder of birth (impossible to recollect), some mother's milk (sometimes not), the affection of relatives (often thoroughly disrupted), perhaps some schooling (mostly not), a bit of play (amid pestilence and panic), and then things end (with or without a rumble). The world goes on as if nothing much has happened.

The situation does, of course, vary from region to region, and from one group to another. But unnecessary suffering, debilitation, and death from preventable or controllable illness characterize every country and every society, to varying extents. As we would expect, the poor countries in Africa or Asia or Latin America provide crudely obvious illustrations of severe deprivation, but the phenomenon is present even in the richest 
countries. Indeed, the deprived groups in the "First World" live, in many ways, in the "Third." For example, African Americans in some of the most prosperous U.S. cities (such as New York, Washington, or San Francisco) have a lower life expectancy at birth than do most people in immensely poorer China or even India. Indeed, location alone may not enhance one's overall longevity.

\section{EXPLANATION AND REMEDY}

How can we come to terms with the extensive presence of such adversity-the most basic privation from which human beings can suffer? Do we see it simply as a human predicament-an inescapable result of the frailty of our existence? That would be correct had these sufferings been really inescapable, but they are far from that. Preventable diseases can indeed be prevented, curable ailments can certainly be cured, and controllable maladies call out for control. Rather than lamenting the adversity of nature, we have to look for a better comprehension of the social causes of horror and also of our tolerance of societal abominations. However, despite many illuminating studies of particular aspects of these general problems, investigators tend to shy away from posing the questions in their full generality. To confront the big picture seems like an overpowering challenge.

Paul Farmer, however, is not easily overpowered. He is a great doctor with massive experience of working against the hardest of diseases in the most adverse of circumstances, and, at the same time, he is a proficient and insightful anthropologist with far-reaching discernment and understanding. Farmer's knowledge of maladies such as AIDS and drug-resistant tuberculosis, which he fights on behalf of his indigent patients, is hard to match. This he combines with his remarkable expertise on culture and society, acquired not just by learning from a distance but also from actually living and working in different parts of the deprived world. In addition, Paul Farmer is a public health interventionist with a dogged determination to work toward changing iniquitous institutions

and mismatched arrangements. As the co-director of Harvard's Program in Infectious Disease and Social Change (working with Dr. Jim Yong Kim, another remarkable public health expert), Farmer has led several major initiatives in changing the direction of health care and intervention (for example, in tackling drug-resistant TB).

But what is particularly relevant in appreciating the contribution of this powerful book is that Paul Farmer is a visionary analyst who can 
look beyond the details of fragmentary explanations to seek an integrated understanding of a complex reality. In his earlier publications, including AIDS and Accusation (I992), The Uses of Haiti (1994), and Infections and Inequalities: The Modern Plagues ( I999), he has already done much to illuminate important features of global deprivations. Now, in this remarkable book, which is hard to put down, comes the big picture, firmly linked with informationally rich illustrations of individual examples.

Farmer points to what he calls "structural violence," which influences "the nature and distribution of extreme suffering." The book is, as he explains, "a physician-anthropologist's effort to reveal the ways in which the most basic right- the right to survive-is trampled in an age of great affluence." He argues: "Human rights violations are not accidents; they are not random in distribution or effect. Rights violations are, rather, symptoms of deeper pathologies of power and are linked intimately to the social conditions that so often determine who will suffer abuse and who will be shielded from harm." Those "social conditions" and their discriminatory effects are the subject matter of this general investigation and the specific case studies that establish the overall picture of powerlessness and deprivation.

\section{CONCEPTS AND METHODS}

Some will undoubtedly ask whether this is not too general, too grand, and perhaps even too ambitious an inquiry. Also, are the questions absolutely clear? How exactly is "power" defined? Does Farmer delineate the "social conditions" precisely? Does he provide an exact definition of "structural violence"? In fact, that is not the way Paul Farmer proceeds, and it is important to understand the methodology that distinguishes this wonderful study.

A phenomenon can be either characterized by a terse definition or described with examples. It is the latter procedure that Farmer follows. That procedure is, of course, quite standard when we learn certain basic words (such as "red" or "smooth"), as Ludwig Wittgenstein (arguably the greatest philosopher of our times) has famously discussed:

An important part of the training will consist in the teacher's pointing to the objects, directing... attention to them, and at the same time uttering a word; for instance the word "slab" as he points to that shape.... This ostensive teaching of words can be said to establish an association between the word and the thing. ${ }^{2}$ 
Though not so primitive as "red" or "smooth" or a "slab," terms like "power" or "violence" can also, often enough, be helpfully communicated through examples.

This is not to deny that we can try to explain these complex terms in other ways as well, in particular by proposing a precise definition through the use of other words. That indeed is the usual procedure, widely used, in the social sciences. And yet, as we know from experience, this is sometimes highly misleading, since the capacious content of a social concept or its diverse manifestations may often be lost or diminished through the maneuver of trying to define it in sharply delineated terms. The expressions "power," "structure," and "violence" are not eccentric inventions of Paul Farmer; they have figured extensively in the literature on social inequality. ${ }^{3}$ But attempts at defining them exactly by other words have typically been inadequate and unclear (and sometimes they have also generated the kind of "sociological jargon" that can sound arrestingly weird). For this reason, among others, the alternative procedure, by exemplification, has many advantages in epistemology and practical reason in parts of the social sciences. The epigrammatic definition, which many social scientists seek, often cannot escape being misleadingly exact; it can be precise but precisely inaccurate. A rich phenomenon with inherent ambiguities calls for a characterization that preserves those shady edges, rather than being drowned in the pretense that there is a formulaic and sharp delineation waiting to be unearthed that will exactly separate out all the sheep from all the goats.

Farmer does not fall for the temptation of a make-believe exactness. While keeping his eyes firmly on the general picture as he sees it, he goes from one case study to another to explain what "structural violence" is like (or how disparity of "power" may operate). We see the evident similarities as well as the rich variations of form and expression. By learning from Farmer's book as a whole, we get an overall understanding that draws together the diverse details spread across these harrowing accounts.

\section{ACÉPHIE'S POWERLESSNESS}

For example, in discussing deprivations in Haiti, Farmer observes that "political and economic forces have structured risk for AIDS, tuberculosis, and, indeed, most other infectious and parasitic diseases" and adds that "social forces at work there have also structured risk for most forms of extreme suffering, from hunger to torture and rape." He discusses in 
each case exactly how this structuring of risk, in distinct forms, blights the lives of many, without touching the affluence of others. He moves from Haiti to Mexico, then to Russia, then to Peru, then to the United States, and right across the world, looking for-and insightfully identifying-institutional structures that push some into the abyss, while others do just fine. The carefully chosen details in each case help us to understand Farmer's notion of "structural violence" through a process that is not altogether dissimilar to the teaching of the idea of a "slab."

Indeed, power inequalities can work in many distinct ways. Take the case of Acéphie, the comely woman born in the small village of Kay through which runs Rivière Artibonite, Haiti's largest river. She is lucky to be born into a prosperous peasant family, but her luck does not last for long. When the valley is flooded to make room for a reservoir, the villagers are forced up into the stony hills on the sides of the new lake. Their voice does not receive a hearing. The displaced people-the "water refugees"-seek whatever jobs they can get (no longer able to grow the rice, bananas, millet, corn, or sugarcane they grew so abundantly earlier), and Acéphie's family ceases to make ends meet. Nevertheless, Acéphie-like other young women in families of water refugees—carries the family's agricultural produce (miserable as it is) to the local market. The soldiers, stationed on the way, watch the procession of girls who walk to the market and often flirt with them. The girls feel lucky to get such attention, since soldiers are powerful and respected men.

When Captain Jacques Honorat woos the tall and fine-featured Acéphie, with her enormous dark eyes, reciprocation eventually follows (even though Acéphie knows that Honorat is married and has several other partners). The sexual relation does not last long, but it is enough to disrupt Acéphie's life, while Captain Honorat dies of unexplained fevers. After trying to qualify herself as a domestic servant in the neighboring town of Mirebalais, the twenty-two-year-old Acéphie moves to Port-au-Prince and finds a servant's job, at a tiny wage. She also begins seeing Blanco Nerette, who comes from a similar background (his parents were also water refugees) and now chauffeurs a small bus, and they plan to marry. However, when Acéphie becomes pregnant, Blanco does not welcome the news at all. Their relationship founders. Also, thanks to her pregnancy, Acéphie loses her job. The battle for economic survival turns intense and is now joined by disease. Acéphie dies of AIDS-loved still by her own family but uncared for and unhelped by society. She leaves behind a daughter, also infected with the virus. That is the beginning of another story, but not a long one. 
The inequalities of power that Acéphie faced in her brief life involved bureaucracy (beginning with displacements to make room for the new reservoir without adequate rearrangement), class (reflected in Acéphie's relations with her employer and with Captain Honorat), gender (related to her standing vis-à-vis the males she encountered-from the soldiers to Blanco), and of course the stratified society (with the absence of public facilities for medical attention and care for the poor). Acéphie did not encounter any physical violence, but Farmer is persuasive in seeing her as a victim of structural violence.

\section{POVERTY, INEQUALITY, AND POWER}

The asymmetry of power can indeed generate a kind of quiet brutality. We know, of course, that power corrupts and absolute power corrupts absolutely. But inequalities of power in general prevent the sharing of different opportunities. They can devastate the lives of those who are far removed from the levers of control. Even their own lives are dominated by decisions taken by others. In one chapter after another, Paul Farmer illustrates the diversity and reach-and also the calamitous consequences-of structural violence. The basic theme and the theses become firmly established through these disparate but ultimately blended accounts. The whole draws on the parts, but firmly transcends them, in the integrated understanding that Farmer advances.

That understanding also suggests lines of thinking about ways of remedying the deprivations and the disparities. For example, if inequality of power, in different forms, is central to deprivation and destitution, then little sense can be made of the frequently aired and increasingly popular slogan, "I am against poverty, but I am really not bothered by inequality." That attempt at a putative dichotomy can be disputed from different perspectives, for example, through an appreciation of the powerful effects of social and economic inequality on the unfreedoms that the subjugated experience. ${ }^{4}$ The proposal to distance inequality from poverty is severely challenged by Farmer's many-sided documentation of the impact of inequality of power on the lives that the subjugated can live. This diagnosis does not, of course, yield any instant solution of the problems; but it does indicate the difficult-and often ignored-social and economic issues that must be firmly faced to eliminate preventable morbidity and escapable mortality.

We live in an age of science, technology, and economic affluence when, as Farmer points out, we can, for the first time in history, deal effectively 
with the diseases that ravage humanity. And yet the reach of science and of globalization has stopped short of bringing reasonable opportunity for survival within the grasp of the deprived masses in our affluent world. This is where the pathologies of power take their toll. As Farmer argues, "Anyone who wishes to be considered humane has ample cause to consider what it means to be sick and poor in the era of globalization and scientific advancement."

Depressing as Farmer's case studies are, their overall message is constructive and optimistic. The solutions are by no means easy, but they are not beyond the reach of our informed and resolute effort. This volume is a major contribution to the understanding that is needed for a determined encounter. We must avoid being like the man, to quote Dryden again, who "trudged along unknowing what he sought, / And whistled as he went for want of thought." Paul Farmer teaches us how to stop whistling and start thinking. We have reason to be grateful. 
This page intentionally left blank 